\title{
Truth, beauty, and perfection
}

$\mathrm{H}$ umanity broadly esteems qualities such as truth, beauty, and perfection that are sometimes hard to define. Most of us have at least primitive ideas of these qualities instilled in us from our youth through the combined efforts of our parents, teachers, and others in our communities. Some of this may be innate. However, as we age, our understanding of these qualities and their ideals often changes.

Philosophers and others, since time immemorial, have asked, "What is truth?" and "What is beauty?" Poets have rhapsodized about both. In one of my favorite poems ("She Walks in Beauty"), George Gordon, Lord Byron, wrote:

She walks in beauty, like the night

Of cloudless climes and starry skies;

And all that's best of dark and bright

Meet in her aspect and her eyes;

Thus mellowed to that tender light

Which heaven to gaudy day denies. ${ }^{1}$

He continues for two more stanzas, rhapsodizing about the qualities that make this woman beautiful. No one reading the poem can doubt that the woman is, in truth, beautiful. Most of us, at one or another point in our lives have formed our own beliefs about human beauty, often attaching those ideas to people for whom we feel love or affection. This brings either joy or suffering, or, more often than not, aspects of both to our lives.

In another poem ("Truth") that I've recently come to appreciate, Stephen Crane had one traveler compare truth to "a rock, a mighty

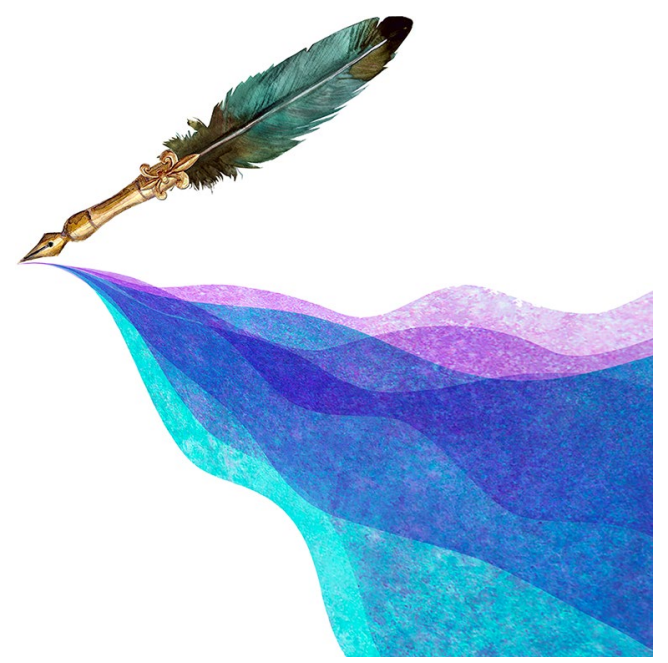

fortress."

But a second traveler compared it to "a breath, a wind, a shadow, a phantom..."; and, as Crane wrote, "Long have I pursued it, but never have I touched the hem of its garment."

If you are reading this article, then

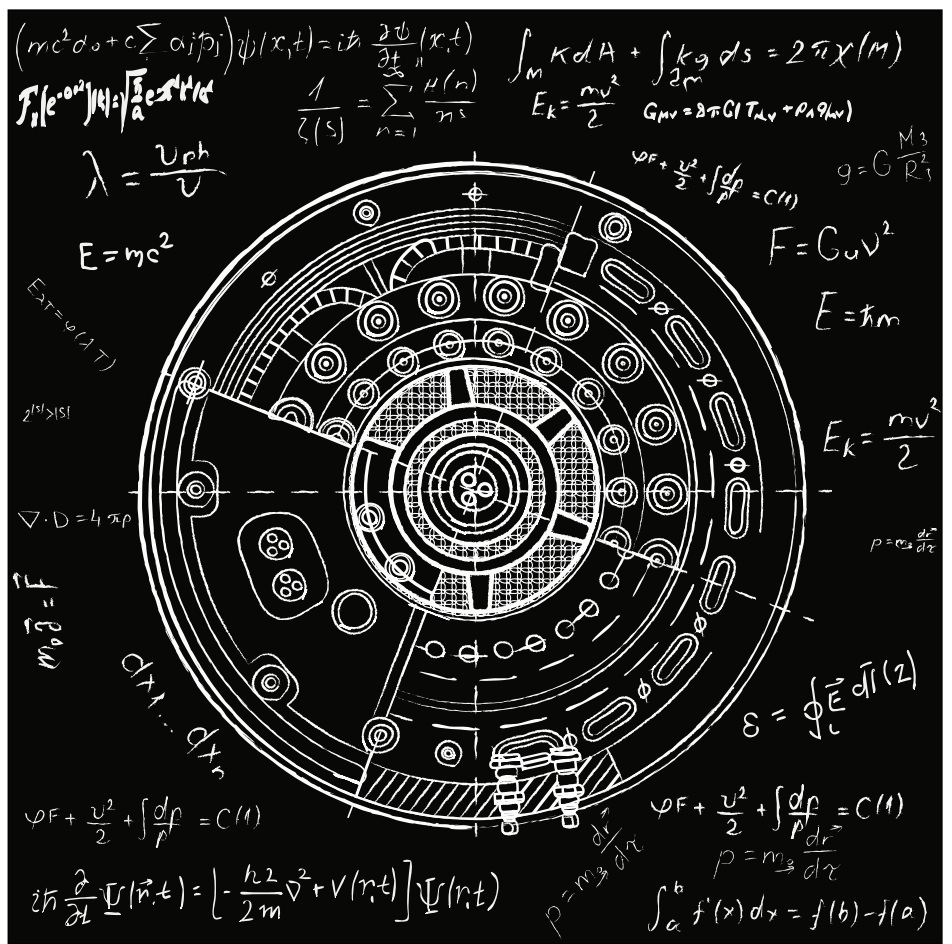

you are most likely someone very interested in materials research. Like most scientists, most of us involved in materials research have sought truth as well as Truth. In addition to our desire to understand materials at a very fundamental level, we also yearn to know the origins of the universe as well as the origins, destinations, and ultimate meaning of human life. We pine to understand mathematical concepts, such as Goldbach's conjecture ${ }^{3}$ (every integer greater than two is the sum of two primes) and the Riemann hypothesis ${ }^{4}$ (concerning the locations of the zeros of the Riemann zeta function). Some of you have likely spent time contemplating Fermat's famous last theorem. ${ }^{5}$ Have you pondered Gödel's work ${ }^{6}$ Do you routinely spend time considering the nature of the special and general theories of relativity $?^{7,8}$ How about quantum measurement theory, ${ }^{9}$ and the many recent measurements that are seemingly incomprehensible, defy logic, and challenge our understanding of truth? Some recent measurements in this area even call into question whether there is or can be

MRS Bulletin welcomes submissions to Posterminaries. Description: Light commentary and observations relating to anything of interest to the MRS Bulletin readership. Topic must have a materials angle. Word play is a plus. Length: 1400-2000 words. Format of submission: Email as a Word document to Bulletin@mrs.org. Examples: mrs.org/posterminaries. 
an objective reality. ${ }^{10}$ Where's the truth (or should I say Truth) in that?

Physicists and other researchers esteem both truth and beauty. So much so, that, for example, the top and bottom quarks, early on, were sometimes called Truth and Beauty. ${ }^{11}$ Although most physicists don't follow this practice today, these names won't go away.

As humans as well as materials researchers, we constantly struggle with issues about truth - in both its absolute sense as well as the narrower issues associated with the "truth" in our own work and belief systems. Much human conflict has resulted from arguments over "Truth" writ large. Nonetheless, we yearn for truth, both as human beings and also as materials researchers. Some of the most interesting activities within materials research have been the urge to uncover the truth about particular materials systems or processes. The extended debate over the microphysical nature of pulsed laser annealing in the early 1980 s was one such endeavor. ${ }^{12}$ Another was related to the activities surrounding claims of the observation of cold fusion. ${ }^{13}$ I note that elements of this latter debate linger on through discussions of what is now called Low Energy Nuclear Reactions (LENRs). ${ }^{14}$ Although much heat was generated in the debates over these issues, as far as I know, no one was killed or physically harmed because of their beliefs.

Wars have been fought over beauty. If you doubt that, read The Iliad of Homer. ${ }^{15}$ (I prefer the translation by Richard Lattimore.) Although the story is myth, no commentary on the story that I've found doubts that a war could have been fought over such beauty. Researchers greatly esteem beauty. Theorists and mathematicians prize beauty in equations. Many believe that the most beautiful equation is Euler's identity ${ }^{16}$

$$
e^{i \pi}+1=0
$$

including, as it does e (the base of the Naperian logarithmic system), pi, the imaginary constant $i$ (the square root of -1 ), and zero. All of these numbers have been the basis of controversy in mathematics.

We materials researchers find beauty in our own work. The Materials Research Society sponsors a Science as Art competition at each Meeting. ${ }^{17}$ Images of structures revealed by electron microscopy and through other means are often stunning in their beauty. If you haven't attended any of those events, I challenge you to view the entries the next time you get a chance. On numerous occasions, I've heard colleagues discuss what they called beautiful experiments. ${ }^{18}$ Such experiments usually involve the skillful teasing of materials properties to produce more perceptive measurements or to extract information at or beyond what was thought to be the limits of our measurement capabilities.

Perfection is another quality humanity esteems. In sports, people discuss bowling a perfect game or pitching a perfect baseball game. People who witness these events revel in the

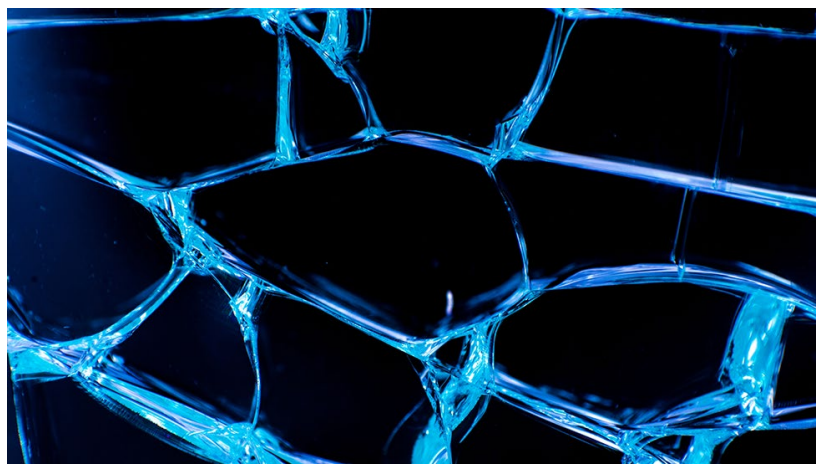

excitement that is engendered as the game progresses toward its ultimate conclusion. I note that these perfect events in sports are rare, but that they do occur. In contrast, perfection outside of sports is a goal for much of humanity, but often an elusive goal and reflects what we perceive about truth. Perfection also plays a role in human concepts of beauty. Much is often made of the role of perfect symmetry in informing our sense of beauty. And yet, others look for beauty in small imperfections in an otherwise perfect form (e.g., a beauty mark) as being necessary for beauty to be sublime. However, perfection is not so easily rendered in materials research. For example, in growth of solids, a perfect crystal would be one without defects. And yet, we know that no crystal at any temperature above absolute zero can be devoid of defects (especially simple point defects such as vacancies and interstitials). ${ }^{19}$ No crystalline lattice extends to infinity. All have boundaries. The boundaries include dangling bonds and other more complicated defects. ${ }^{20}$ Can we, as materials researchers, contemplate perfection through a framework that is manifestly imperfect? It seems so, because we are constantly striving to move the imperfect as close to perfection as we can get, and sometimes find perfection by controlling imperfections rather than eliminating them (G. Rao, personal communication).

Truth, beauty, and perfection are conceptual attributes developed by humanity. In their rawest form, they live as ideals that challenge us. In materials research, those challenges drive us toward development of new and better materials, more perceptive measurement techniques and measurements, as well as better understanding of the properties of materials. I would like to close by saying that all of this effort in materials research is directed toward goals that help humanity. And yet, I know that this is not true. Alas, perhaps the most essential truth of all is that materials research can be directed toward projects that threaten humanity at very fundamental levels. Where's the beauty in that? While I firmly believe that the vast majority of materials researchers direct their efforts for the betterment of humankind, we must always be aware of the potential for applications that are not in the best interests of humanity.

Steve Moss 


\section{References}

1. https://www.poetryfoundation.org/poems/43844/she-walks-in-beauty

2. https://poets.org/poem/xxviii-truth-said-traveller

3. https://en.wikipedia.org/wiki/Goldbach\%27s_conjecture

4. https://www.google.com/search?q=riemann+conjecture\&oq=riemann+conjecture\& aqs $=$ chrome. .69i57j0I2j0i22i30I2.6141j0j4\&sourceid $=$ chrome\&ie $=U T F-8$

5. S. Sing, Fermat's Last Theorem (Harper Collins, New York, 2002)

6. E. Nagel, J.R. Newman, Gödel's Proof, rev. ed. (New York University Press, New York, 2008)

7. N.D. Mermin, It's About Time: Understanding Einstein's Relativity (Princeton University Press, Princeton, NJ, 2021)

8. S.M. Carroll, Spacetime and Geometry: An Introduction to General Relativity, 1st ed. (Cambridge University Press, Cambridge, UK, 2019)

9. T. Norsen, Foundations of Quantum Mechanics: An Exploration of the Physical Meaning of Quantum Theory, 1st ed. (Springer, Cham, Switzerland, 2017)
10. https://www.livescience.com/quantum-paradox-throws-doubt-on-observed-reality $\mathrm{html}$

11. https://en.wikipedia.org/wiki/Quark

12. M.O. Thompson, S.T. Picraux, J.S. Williams, in MRS Online Proceedings Library Archive, vol. 74 (1986)

13. J.R. Huizenga, Cold Fusion: The Scientific Fiasco of the Century (University of Rochester Press, Rochester, NY, 1993)

14. https://spectrum.ieee.org/tech-talk/energy/nuclear/cold-fusion-or-low-energy-nucle ar-reactions-us-navy-researchers-reopen-case

15. The Iliad of Homer, trans. R. Lattimore (University of Chicago Press, Chicago, 2011)

16. https://en.wikipedia.org/wiki/Euler\%27s_identity

17. https://www.mrs.org/programs-outreach/science-as-art/science-as-art-archives

18. G. Johnson, The Ten Most Beautiful Experiments, 1st ed. (Vintage Books, New York, 2008)

19. M.D. McCluskey, E.E. Haller, Dopants and Defects in Semiconductors, 1st ed. (CRC Press, Boca Raton, FL, 2012)

20. H. Lüth, Solid Surfaces, Interfaces and Thin Films, 6th ed., 2015 ed. (Springer, Berlin, Germany, 2014)

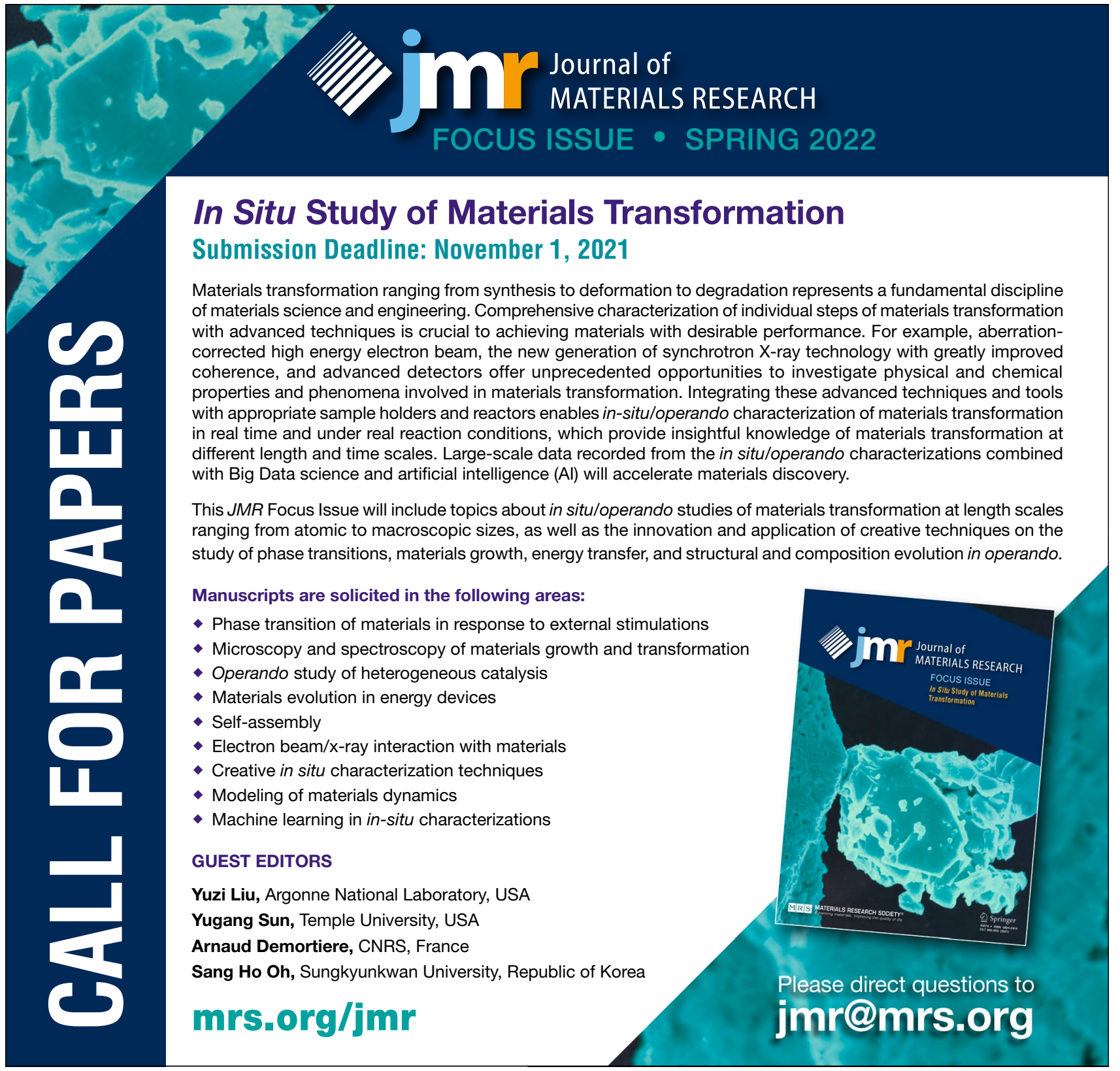

